\title{
In search of conserved principles of planar cell polarization
}

Jules Lavalou ${ }^{1,2, *}$ and Thomas Lecuit ${ }^{1,2,{ }^{*}}$

1. Aix-Marseille Université \& CNRS, IBDM - UMR7288 \& Turing Centre for Living Systems, Marseille, France

2. Collège de France, Paris, France

*Corresponding authors: jules.lavalou@univ-amu.fr, thomas.lecuit@univ-amu.fr

\begin{abstract}
The making of an embryo and its internal organs entails the spatial coordination of cellular activities. This manifests during tissue morphogenesis as cells change shape, rearrange and divide along preferential axis and during cell differentiation. Cells live in a polarized field and respond to it by polarizing their cellular activities in the plane of the tissue by a phenomenon called planar cell polarization. This phenomenon is ubiquitous in animals and depends on a few conserved planar cell polarity (PCP) pathways. All PCP pathways share two essential characteristics: the existence of local interactions between protein complexes present at the cell surface leading to their asymmetric distribution within cells; a supracellular graded cue that aligns these cellular asymmetries at the tissue level. Here, we discuss the potential common principles of planar cell polarization by comparing the local and global mechanisms employed by the different PCP pathways identified so far. The focus of the review is on the logic of the system rather than the molecules per se.
\end{abstract}

\section{Introduction}

Planar cell polarity (PCP) aligns the polarity of cell sheets within the plane of the tissue, perpendicularly to the apico-basal axis [1-4]. Planar polarized processes are ubiquitous in animals and involved in a wide variety of cell behaviors both in epithelial and non-epithelial cells [5], such as the polarization of differentiated cell structures (Figure 1a), oriented cell division (Figure 1b), polarized cell rearrangements (Figure $1 \mathrm{c}$ and Figures $2 \mathrm{a}, \mathrm{c}$ ) or directed collective cell migration (Figure $2 \mathrm{~b}$ ). Despite their diversity, PCP processes are controlled by a limited number of PCP pathways. To date, four PCP signaling pathways have been identified [1-4]: the highly conserved so called "core" PCP (Figure 1a$\mathrm{c}^{\prime \prime}$ ), involving the transmembrane proteins Flamingo (Fmi, CELSR in mammals), Frizzled (Fz) and Van Gogh (Vang, also known as Strabismus), on which most of the studies on planar polarity have focused so far; the "Fat/Dachsous" (Ft/Ds) PCP (Figure 2a-a"); the "Fat2/Lar" PCP (Figure 2b-b"); and the recently found "Toll-8/Cirl" PCP (Figure 2c-c") [6]. 
Some PCP processes happen in rather static tissues while others happen in tissues undergoing constant remodeling; some are unipolar (i.e. vectorial) while others are bipolar. PCP pathways usually polarize cell behaviors by polarizing the actomyosin and microtubule cytoskeleton [5]. To give a few examples, core PCP is required for the orientation of wing hairs in Drosophila $[7,8]$, hair follicles in mammals $[9,10]$ and hair cells in the mammalian inner ear [11-13], for cell intercalation leading to convergent extension in mammalian epithelial [14,15] and non-epithelial tissues [16-19], and for oriented cell divisions in Drosophila [20-22] and zebrafish [22,23]; Ft/Ds PCP is required for wing and thorax morphogenesis in Drosophila [24,25]; Fat2/Lar PCP is required for collective migration in Drosophila egg chambers [26,27]; Toll-8/Cirl PCP is required for cell intercalation leading to tissue elongation in Drosophila $[6,28,29]$, a process at least partially conserved in several arthropod species [30].

One of the most salient feature of PCP is the fact that cells exhibit an intrinsic orientation (i.e. polarity), which they need to coordinate with their neighbors with respect to a tissue axis. An important characteristic of planar polarity proteins (i.e. members of a given PCP pathway) is that they display complementary planar polarized distributions at the cell level (Figure 1 and Figure 2, right columns). Two types of polarized distribution of proteins can be distinguished: axial (bipolar) planar polarity in which proteins are enriched on both sides along one planar axis of a cell and depleted from the junctions in the other planar axis; and vectorial (unipolar) planar polarity in which proteins are enriched on only one side of a cell. For example, in the core PCP, Fmi displays an axial polarity while Fz and Vang display complementary vectorial polarities (Figure 1a") [31].

Although a variety of cell behaviors are oriented by PCP processes, important similarities can be observed between these different phenomena. The purpose of this review is to delineate potential common principles as well as differences that emerge from comparing these different pathways of planar cell polarization.

\section{Local interactions between asymmetric planar polarity complexes}

A hallmark of PCP processes is that neighboring cells adopt a coordinated polarity under the dependence of planar polarity proteins [2]. This coordination of polarity is due to self-organized positive feedback between intercellular asymmetric transmembrane protein complexes. Despite the specificities of the different PCP pathways, common principles are at stake at the molecular level: PCP pathways involve transmembrane proteins with adhesion motifs, which interact in trans between neighboring cells and mutually polarize each other via feedbacks. This behavior is particularly obvious when one PCP protein is asymmetrically expressed between two groups of cells, leading to the recruitment of the complementary PCP protein complex at the interfaces between these two groups of cells (Figure 3a-c).

To form these asymmetric intercellular complexes, planar polarity proteins with extracellular adhesion motifs play a crucial role. Two families of proteins appear to be involved in the formation of these trans-complexes: adhesion GPCRs, like Fmi and Cirl, and atypical cadherins, like Ft, Ds and Fat2. Transcomplexes formation results from trans-heterophilic interactions between planar polarity proteins (Ft/Ds; Toll-8/Cirl; Fat2/Lar) except for Fmi that requires homophilic interactions between its cadherin domains. However, evidence suggests that Fmi exists in two functional forms, depending on its binding to Fz or Vang, explaining how a homophilic binding protein can form asymmetric bridges [32-34]. 
We will now present examples of polarity coordination observed in the different PCP pathways and the molecular mechanism underlying the formation of these complementary asymmetric complexes. In this part, we will detail examples arising from Drosophila studies, where the most extensive molecular characterizations of PCP pathways have been done, but similar principles are likely at work in other organisms including mammals.

\section{Core PCP}

The first examples of coordinated polarity due to asymmetric expression of PCP proteins were described in the core PCP. For example, vang mutant clones (i.e. groups of cells that express only Fz) recruit Vang and repel $\mathrm{Fz}$ from their wild-type neighboring cells while $\mathrm{Fz}$ inside the clone accumulates at the interface with wild-type cells (Figure 3a) [32,35].

This phenomenon of mutual attraction is due to the fact that $\mathrm{Fz}$ and Vang mutually polarize each other in a Fmi-dependent manner. Fmi can form protein complexes either with $\mathrm{Fz}$ or Vang, through different protein domains, and its stability at junctions depends on the formation of asymmetric complexes between Fmi:Fz in one cell and Fmi:Vang in the adjacent cell (Figure 3a') [32,33]. One hypothesis is that Fmi exists in two functional forms: Fmi associated with Vang (V-Fmi) and Fmi associated with Fz (F-Fmi), with preferential interaction between V-Fmi and F-Fmi instead than between the same form, explaining how asymmetric protein complexes can be formed [32].

Once an intercellular asymmetry between transmembrane complexes is in place, self-stabilization and mutual destabilization of asymmetric complexes amplify the initial asymmetry through the cytoplasmic core PCP proteins (Dishevelled (Dsh), Diego (Dgo) and Prickle (Pk)). Dsh interacts with Fz [36] while Pk interacts with Vang [35]. Dsh and Pk can also bind to each other, which destabilizes Dsh membrane association [37]. Moreover, Dgo also binds to Dsh via the same domain as Pk in a mutually exclusive manner [38]. Thus, on one side of the cell Pk binds to Dsh in order to destabilize it from this side while Dgo binds to Dsh on the other side of the cell, blocking the binding of Pk and stabilizing Dsh there (Figure 3a').

The prevailing view is that the transmembrane core PCP proteins first form stable asymmetric complexes independently of the cytoplasmic proteins, which in a second step promote the formation of puncta resistant to endocytosis in cis (stabilization) or promote endocytosis in trans (destabilization), strengthening the initial asymmetry [39]. Notably, computational models combining intercellular and intracellular feedback loops successfully recapitulated the experimental observations of core PCP patterns $[40,41]$.

\section{Ft/Ds PCP}

Similar to what have been observed in the core PCP, asymmetric expression of Ft or Ds in a group of cells leads to a mutual polarization at the interface of this group of cells $[42,43]$. For example, in the last row of cells of a $\mathrm{ft}$ mutant clone, Ds is lost from the internal junctions of the clone accumulating at the interface with the wild-type tissue while Ft accumulates in trans (from wild-type cells) at this interface (Figure 3b) [42].

What is the mechanism underlying this mutual attraction? Ft and Ds are protocadherins with a preferential heterophilic binding in trans and are mutually required for their proper junctional 
localization [42-44]. The Golgi kinase Four-joint ( $\mathrm{Fj}$ ) can phosphorylate the cadherin domains of $\mathrm{Ft}$ and Ds [45] and modulates the affinity of their binding (Figure 3b') [46,47].

\section{Toll-8/Cirl PCP}

Following similar principles, when Toll-8 is overexpressed in clones, Cirl is planar polarized in trans in wild-type cells in contact with the clone boundary [6] (Figure 3c). Furthermore, quantitative differences in Toll-8 expression between neighboring cells leads to Toll-8 planar polarity, which induces Cirl planar polarity (Figure 3c).

Moreover, Cirl is required for Toll-8 planar polarity, indicating that Toll-8 and Cirl planar polarity are mutually dependent on each other via a positive feedback mechanism (Figure $3 c^{\prime}$ ). Toll-8 and Cirl form a molecular complex suggesting that they may directly interact with each other [6]. Thus, the mechanisms behind the mutual polarization of Toll- 8 and Cirl between the two sides of a cell interface are akin to what has been observed in the core PCP and in the Ft/Ds PCP.

\section{Fat2/Lar PCP}

Fat2 and Lar, which are respectively an atypical cadherin and a receptor tyrosine phosphatase, are planar polarized during follicle rotation in Drosophila $[48,49]$. Fat 2 is enriched at the trailing edge while Lar is enriched at the leading edge of each cell (Figure $3 \mathrm{~d}$ ) and they colocalize in puncta suggesting that they participate in an intercellular signaling complex [27].

Mechanistically, Fat2 is required non-cell autonomously to recruit Lar in trans in the cell behind (Figure $\left.3 d^{\prime}\right)$. However, the absence of Lar has less effect on Fat2 localization [27], indicating that they are not mutually required for their respective polarization. Moreover, it has not been tested whether clonal overexpression of Fat2 or Lar polarize the complementary protein in trans. Thus, the Fat2/Lar system shares similarities with the other PCP systems (planar polarized patterns and presence of protein with adhesion motifs) but Fat2 and Lar are not mutually required for their proper localization and are not attracted at sites of asymmetric expression of the complementary proteins.

\section{Global alignment and propagation of planar polarity}

We have considered, so far, the mechanisms of local coordination of cell polarities. But a major characteristic of PCP pathways is that planar polarity vectors at the cell levels are coordinated at a large scale, as they are aligned with respect to a tissue axis. Most models propose that the alignment of cell polarity across the tissue arise from a graded cue, chemical or mechanical, as a gradient can provide both an axis and a vector of orientation [50,51]. We propose to distinguish two different mechanisms of polarization: the case where the graded polarity cue is external to the system, i.e. the expression pattern of planar polarity proteins does not instruct their axis and vector of polarity; and the case where the graded polarity cue is internal to the system, i.e. planar polarity proteins are themselves expressed in a gradient that instruct the axis and vector of polarity. 


\section{External polarity cues}

\section{Core PCP}

Classical models proposed that a gradient of morphogen aligned the polarity of the core PCP proteins along the tissue axis.

The first hypothesis emerging from studies in Drosophila was that that a gradient of Fz activity provides the global cue for core PCP alignment [52]. However, no such gradient of Fz activity has been observed in vivo. Wnts are secreted glycoproteins that bind $\mathrm{Fz}$, are expressed as gradients in tissues and were suggested to provide a long-range polarizing cue [53] but more recent reports show that a Wnts gradient is unlikely to be the instructive cue aligning PCP $[54,55]$. In certain systems, like the developing mouse limb, a Wnt5 gradient was suggested to be essential for the alignment of PCP across the tissue [56] but recent studies indicated that this gradient could also play a more permissive role in this system [57].

The Ft/Ds complex was also suggested to provide the global cue that orients core PCP since Ds and Fj are expressed in gradients, and their loss affects planar polarity [42,44,58]. However, uniform expression of Ds and Fj is sufficient for the proper alignment of core PCP in the Drosophila wing $[25,43]$, indicating that their graded expressions are not required. Thus, Ft/Ds complex is likely to be mainly a permissive rather than an instructive cue that aligns core PCP proteins.

While Notch, Wg, Hedgehog, Dpp, Ft and Ds are expressed as gradients in Drosophila wing discs, flattening their expressions by overexpression does not reduce polarization, as would be predicted if their graded expressions were important, but rather reorient the PCP vectors in correlation with changes in tissue growth [59]. This suggests that gradients orient PCP through their multiple roles in morphogenesis rather than through their graded expressions.

Recently, mechanical forces emerged as a graded cue that can align PCP across a tissue. In the Drosophila wing, PCP reorients during a morphogenetic movement and blocking this movement strongly affects PCP patterns [25]. Moreover, morphogenesis is perturbed in the absence of the Ft/Ds complex [25], suggesting that it plays a role in PCP through its role in morphogenesis. Similarly, in mammalian hair follicles, Fmi asymmetry emerges due to a gradient of tissue deformation and applying an exogenous stretch is sufficient to reorient Fmi polarity [60]. Because PCP proteins are stable at persistent junctions but take time to accumulate at newly-formed junctions, oriented neighbor exchange induced by morphogenetic movements can guide the axis of polarity (Figure 4a) $[25,50,60,61]$. Therefore, one model is that oriented cell intercalations generated by morphogenesis result in a spontaneous symmetry breaking of PCP proteins both in mammals and in Drosophila, and this initial polarity is then amplified by local feedbacks between PCP proteins.

Microtubule orientation is also a very attractive potential cue. In the Drosophila wing, microtubules are preferentially aligned along the same axis as core PCP proteins and disrupting the microtubule network strongly perturbs core PCP proteins distribution [62]. Moreover, microtubules plus-end show a vectorial orientation and Fz particles move toward this direction (Figure 4a') [62], suggesting a directed transport of $\mathrm{Fz}$ by microtubules. Furthermore, $\mathrm{Ft}$ and $\mathrm{Ds}$ are required for microtubule alignment $[63,64]$, thus the Ft/Ds complex might affect the core PCP by playing a role in the orientation of the microtubule network that delivers Fz:Dsh preferentially to the distal side of the cell. In Xenopus, microtubules and PCP proteins participate in a positive feedback loop to align the axis of planar polarity in the skin [65]. In this system, PCP proteins are required for microtubule alignment and microtubules are required for core PCP proteins accumulation. Imposing a mechanical strain was sufficient to align 
microtubules along the tissue even in the absence of core PCP proteins [65], suggesting that core PCP proteins, microtubules and mechanical forces participate in a feedback loop.

Therefore, the alignment of core PCP proteins over long-distance does not seem to be simply determined by a chemical gradient as initially hypothesized. Several cues determine PCP alignment at different stages by playing a role in morphogenesis (i.e. cell dynamics) and/or in microtubule orientation. Interestingly, morphogenetic forces can align microtubules along a tissue axis and microtubules can likely affect morphogenesis due to their pleiotropic role. This might explain why it is so difficult to identify a unique cue aligning polarity: morphogenetic gradients probably affect both mechanics and microtubules orientation in a tissue, and mechanics and microtubules orientation likely feedback on each other. Importantly, core PCP proteins are required in several morphogenetic processes both in mammals and in Drosophila and are especially involved in planar polarized contractility $[14,15,18,19,66-71]$. Thus, the core PCP proteins may amplify their own polarization through the very morphogenetic processes they control. This will require further investigation.

\section{Fat2/Lar PCP}

During follicle rotation in Drosophila, microtubules are aligned early in the process and are required for tissue rotation [72]. Their plus-end grows in the direction opposite to tissue rotation and this orientation can predict the direction of tissue rotation [72]. Microtubules are still aligned within each cell in absence of Fat2 but their global alignment in the tissue is lost and the polarity of their growing plus-end is randomized [72,73]. Fat2 polarity is also affected when microtubules polymerization is blocked [72], suggesting a feedback amplification mechanism between Fat2 localization and microtubule polarity required for symmetry breaking.

Later in the process, tissue rotation is essential for the tissue-scale alignment of actin bundles in a noncell autonomous manner and for Fat2 and Lar planar polarity $[26,27,74,75]$. During tissue rotation, a polarized basement membrane is deposited and aligned in the tissue with the same orientation as the actin bundles [76]. This requires the presence and regulation of integrins, suggesting that tissue rotation is required for basement membrane polarization $[76,77]$.

The consensus is that feedback mechanisms between Fat2 polarization and microtubules polarity constitute the initial symmetry breaking cue, which is aligned in the tissue by intercellular short-range communication involving Fat2 and Lar. Fat2 and Lar then induce actin polymerization at the leading edge of each cell, leading to tissue rotation that is required to maintain and amplify their own polarities. Therefore, as in the core PCP, there is a feedback between the planar polarity proteins Fat2/Lar, microtubule orientation and tissue mechanics to align planar polarity along the tissue axis (Figure 4b).

\section{Internal polarity cues}

\section{$F t / D s P C P$}

In the $\mathrm{Ft} / \mathrm{Ds} \mathrm{PCP}$, the planar polarity proteins are themselves acting as the graded polarizing cue. Indeed, $\mathrm{Fj}$ and $\mathrm{Ds}$ are expressed as tissue-wide opposing transcriptional gradients in many Drosophila tissues $[2,42-44,58]$. Ft and Ds are asymmetrically distributed on opposite cell sides in specific domains of these expression gradients leading to asymmetric localization of the atypical myosin Dachs 
$[24,78,79]$. Contrary to the effect of Ft/Ds on core PCP, uniform expressions of Ds or Fj disrupt the asymmetric distribution of Ft, Ds and Dachs $[24,79]$. Therefore, the consensus is that Ft and Ds are polarized in domains where $\mathrm{Fj}$ and $\mathrm{Ds}$ transcriptional gradients intersect, leading to Dachs planar polarity (Figure 4c). Computational modelling can reproduce these patterns, showing that opposing tissue-wide gradients of $\mathrm{Fj}$ and $\mathrm{Ds}$ coupled with preferential trans-heterophilic binding between $\mathrm{Ft}$ and Ds modulated by Fj levels are sufficient to explain the planar polarized patterns observed in vivo $[80,81]$.

\section{Toll-8/Cirl PCP}

Recently, it was found that differential expression of Toll-8 between neighboring cells leads to mutually dependent Toll-8 and Cirl planar polarity [6]. When Toll-8 is expressed with quantitative differences between neighboring cells, Toll-8 is planar polarized in cells expressing lower levels of Toll-8 and accumulates at interfaces facing away from the cells expressing higher levels of Toll-8. Thus, the direction of the spatial differences in Toll-8 expression directs the orientation of Toll-8/Cirl/Myo-II planar polarity (Figure 4d), as the gradients of Fj and Ds in the Ft/Ds PCP. In the Toll-8/Cirl PCP, a single transcriptional gradient is able to generate planar polarity, while the Ft/Ds PCP requires two opposing gradients. Whether Toll-8 can be endogenously expressed as a tissue gradient in vivo requires further investigations but evidence suggest it might be the case in early Drosophila embryos [82].

Cirl and adhesion GPCRs are known to be involved in mechanosensation [83-85]. Considering that Cirl induces Myosin-II enrichment and polarized contractility, it would be interesting to assess whether the mechanical tension induced by Toll-8/Cirl plays a role of positive feedback to amplify planar polarity. This hypothesis is supported by the fact that there is a feedback between mechanical tension and planar polarity in Drosophila embryos [86,87], where Tolls receptors and Cirl are required for planar polarized contractility $[6,28]$.

A common characteristic of PCP pathways is the use of tissue-wide graded cue to align PCP vector along a tissue axis. Two strategies can be distinguished: transcriptional expression gradients of planar polarity proteins (internal polarity cues), which can coordinate polarity on a range of few cells; and tissue mechanics and microtubules polarity (external polarity cues), which can align polarity over longrange and are often themselves regulated by PCP pathways leading to feedback and amplification.

\section{Conclusions and perspectives}

To conclude, despite the numerous processes they control and their molecular specificities, PCP pathways share important features. At their core, transmembrane proteins form asymmetric bridges by attracting each other in trans via positive feedback loops. Transmembrane proteins with adhesion motifs, from the adhesion GPCR or atypical cadherin families, play a crucial role in the formation of these asymmetric bridges. These local interactions are then propagated and aligned globally according to a tissue axis through graded cues, which can be internally encoded in the system or coming from 
external sources. Importantly, these two levels (local and global) are not independent from each other. For example, mechanical forces align planar polarity in a tissue and PCP proteins can regulate tissue mechanics. Microtubules are at a crossroad of these feedback: they can regulate PCP protein localization through directed transport and through their role in tissue mechanics; and their polarization is controlled by planar polarity proteins and tissue mechanics. Thus, feedback happens at each step of PCP processes.

Moreover, PCP systems are not independent from each other and their connections are tightly regulated in vivo. A case study is the connection between the core PCP and the Ft/Ds PCP [88], which has been puzzling to understand since they are connected in some Drosophila tissue such as the wing and the eye, but independent in other tissues like the abdomen [89]. These contradicting observations can now be reconciled. Indeed, the prickle locus produces two different isoforms: one of them is independent of the Ft/Ds PCP while the other connects the core PCP with the Ft/Ds PCP [90]. Therefore, the presence of regulatory layers upstream of PCP systems complicates their understanding as independent units and push in favor of adopting an integrated view when studying PCP systems.

Last but not least, a major challenge in the following years will be to address the conservation of PCP systems in mammals. Indeed, Drosophila is an ideal system to study PCP, especially given the ease of use of mosaic analysis. In the last 15 years, major findings showed the important conservation at the molecular level of the core PCP between Drosophila and mammals. Interestingly, the mammalian genome encodes orthologues of the Ft/Ds PCP playing important role to polarize developmental processes $[2,91,92]$. Fat2 has mammalian orthologues that are involved in cell migration but no counterparts for Lar were identified yet [93]. Finally, Toll-8/Cirl PCP is also likely conserved in mammals. Indeed, Toll receptors share sequence similarities with vertebrate FLRTs [94], which are known binding partners of Cirl vertebrate orthologues latrophilins, and are involved in cell sorting [95] and organ development [96]. Therefore, as the core PCP, the three other PCP pathways found in Drosophila also share mammalian counterparts but little is known about the conservation of their molecular functions. Future studies will be required to investigate the potential conservation of these pathways.

The comparison of these different systems opens an avenue for identifying conserved mechanistic principles rather than molecules. The conservation of logic is ultimately the most important aspect of the problem to consider. The further comparison of multiple systems in different organisms will pave the way for deciphering such principles.

\section{Conflict of interest statement}

Nothing declared.

\section{Acknowledgements}

The authors thank all members of the Lecuit group and B. Aigouy (IBDM, France) for stimulating discussions and useful feedback on this manuscript. The lab is supported by the ERC grant SelfControl \#788308 and the Ligue contre le Cancer. J.L. and T.L. are supported by the Collège de France. 


\title{
References
}

\author{
* of special interest \\ ** of outstanding interest
}

1. Devenport D: The cell biology of planar cell polarity. J Cell Biol 2014, 207:171-179.

2. Goodrich L V., Strutt D: Principles of planar polarity in animal development. Development 2011, 138:1877-1892.

3. Bayly R, Axelrod JD: Pointing in the right direction: New developments in the field of planar cell polarity. Nat Rev Genet 2011, 12:385-391.

4. Butler MT, Wallingford JB: Planar cell polarity in development and disease. Nat Rev Mol Cell Biol 2017, 18:375-388.

5. Devenport D: Tissue morphodynamics: Translating planar polarity cues into polarized cell behaviors. Semin Cell Dev Biol 2016, 55:99-110.

** 6. Lavalou J, Mao Q, Harmansa S, Kerridge S, Lellouch AC, Philippe J-M, Audebert S, Camoin L, Lecuit $\mathrm{T}$ : Formation of polarized contractile interfaces by self-organized Toll-8/Cirl GPCR asymmetry. Dev Cell 2021, 56:1574-1588.e7.

In this article, the authors report that Toll-8 controls myosin-II planar polarity in Drosophila embryos and wing discs via a physical interaction with the GPCR Cirl/latrophilin. Thanks to the use of mosaic analysis, they show that Toll-8 expression boundaries generate a Cirl interfacial asymmetry and propose that it is a potential signal leading to myosin-II polarization.

7. Gubb D, Garcia-Bellido: A genetic analysis of the determination of cuticular polarity during development in Drosophila melanogaster. J Embryol Exp Morphol 1982, Vol. 68:37-57.

8. Wong LL, Adler PN: Tissue polarity genes of Drosophila regulate the subcellular location for prehair initiation in pupal wing cells. J Cell Biol 1993, 123:209-221.

9. Devenport D, Fuchs E: Planar polarization in embryonic epidermis orchestrates global asymmetric morphogenesis of hair follicles. Nat Cell Biol 2008, 10:1257-1268.

10. Guo N, Hawkins C, Nathans J: Frizzled6 controls hair patterning in mice. Proc Natl Acad Sci U S A 2004, 101:9277-9281.

11. Montcouquiol M, Rachel RA, Lanford PJ, Copeland NG, Jenkins NA, Kelley MW: Identification of Vangl2 and Scrb1 as planar polarity genes in mammals. Nature 2003, 423:173-177.

12. Curtin JA, Quint E, Tsipouri V, Arkell RM, Cattanach B, Copp AJ, Henderson DJ, Spurr N, Stanier $P$, Fisher EM, et al.: Mutation of Celsr1 disrupts planar polarity of inner ear hair cells and causes severe neural tube defects in the mouse. Curr Biol 2003, 13:1129-1133.

13. Wang J, Mark S, Zhang X, Qian D, Yoo SJ, Radde-Gallwitz K, Zhang Y, Lin X, Collazo A, WynshawBoris $A$, et al.: Regulation of polarized extension and planar cell polarity in the cochlea by the vertebrate PCP pathway. Nat Genet 2005, 37:980-985.

14. Nishimura $\mathrm{T}$, Honda $\mathrm{H}$, Takeichi M: Planar cell polarity links axes of spatial dynamics in neuraltube closure. Cell 2012, 149:1084-1097. 
15. Butler MT, Wallingford JB: Spatial and temporal analysis of PCP protein dynamics during neural tube closure. Elife 2018, 7:1-23.

16. Heisenberg CP, Tada M, Rauch GJ, Saúde L, Concha ML, Geisler R, Stemple DL, Smith JC, Wilson SW: Silberblick/Wnt11 mediates convergent extension movements during zebrafish gastrulation. Nature 2000, 405:76-81.

17. Wallingford JB, Rowning BA, Vogell KM, Rothbächer U, Fraser SE, Harland RM: Dishevelled controls cell polarity during Xenopus gastrulation. Nature 2000, 405:81-85.

18. Kim SK, Shindo A, Park TJ, Oh EC, Ghosh S, Gray RS, Lewis RA, Johnson CA, Attie-Bittach T, Katsanis $\mathrm{N}$, et al.: Planar cell polarity acts through septins to control collective cell movement and ciliogenesis. Science 2010, 329:1337-1340.

19. Shindo A, Wallingford JB: PCP and septins compartmentalize cortical actomyosin to direct collective cell movement. Science 2014, 343:649-652.

20. Gho $\mathrm{M}$, Schweisguth $\mathrm{F}$ : Frizzled signalling controls orientation of asymmetric sense organ precursor cell divisions in Drosophila. Nature 1998, 393:178-181.

21. Bellaïche $\mathrm{Y}$, Gho M, Kaltschmidt JA, Brand AH, Schweisguth F: Frizzled regulates localization of cell-fate determinants and mitotic spindle rotation during asymmetric cell division. Nat Cell Biol 2001, 3:50-57.

22. Ségalen M, Johnston CA, Martin CA, Dumortier JG, Prehoda KE, David NB, Doe CQ, Bellaïche Y: The Fz-Dsh Planar Cell Polarity Pathway Induces Oriented Cell Division via Mud/NuMA in Drosophila and Zebrafish. Dev Cell 2010, 19:740-752.

23. Gong $\mathrm{Y}, \mathrm{Mo} \mathrm{C}$, Fraser SE: Planar cell polarity signalling controls cell division orientation during zebrafish gastrulation. Nature 2004, 430:689-693.

24. Bosveld F, Bonnet I, Guirao B, Tlili S, Wang Z, Petitalot A, Marchand R, Bardet PL, Marcq P, Graner F, et al.: Mechanical control of morphogenesis by fat/dachsous/four-jointed planar cell polarity pathway. Science 2012, 336:724-727.

25. Aigouy B, Farhadifar R, Staple DB, Sagner A, Röper JC, Jülicher F, Eaton S: Cell Flow Reorients the Axis of Planar Polarity in the Wing Epithelium of Drosophila. Cell 2010, 142:773-786.

26. Cetera $\mathrm{M}$, Horne-Badovinac $\mathrm{S}$ : Round and round gets you somewhere: Collective cell migration and planar polarity in elongating Drosophila egg chambers. Curr Opin Genet Dev 2015, 32:1015.

** 27. Barlan K, Cetera M, Horne-Badovinac S: Fat2 and Lar Define a Basally Localized Planar Signaling System Controlling Collective Cell Migration. Dev Cell 2017, 40:467-477.e5.

In this article, the authors report that Fat2 and Lar show complementary asymmetric distributions during Drosophila egg chamber rotation, with Fat2 enriched at the trailing edge and Lar enriched at the leading edge of each cell. Using elegant mosaic experiments, they show that Lar promotes actin protrusions cell autonomously while Fat2 promotes protrusions in the leading edge of the cell directly behind.

28. Paré AC, Vichas A, Fincher CT, Mirman Z, Farrell DL, Mainieri A, Zallen JA: A positional Toll receptor code directs convergent extension in Drosophila. Nature 2014, 515:523-527.

29. Tamada M, Shi J, Bourdot KS, Supriyatno S, Palmquist KH, Gutierrez-Ruiz OL, Zallen JA: Toll receptors remodel epithelia by directing planar-polarized Src and PI3K activity. Dev Cell 2021, 56:1589-1602.e9. 
30. Benton MA, Pechmann M, Frey N, Stappert D, Conrads KH, Chen YT, Stamataki E, Pavlopoulos A, Roth S: Toll Genes Have an Ancestral Role in Axis Elongation. Curr Biol 2016, 26:1609-1615.

31. Strutt H, Strutt D: Asymmetric localisation of planar polarity proteins: Mechanisms and consequences. Semin Cell Dev Biol 2009, 20:957-963.

32. Chen WS, Antic D, Matis M, Logan CY, Povelones M, Anderson GA, Nusse R, Axelrod JD: Asymmetric Homotypic Interactions of the Atypical Cadherin Flamingo Mediate Intercellular Polarity Signaling. Cell 2008, 133:1093-1105.

33. Strutt H, Strutt D: Differential Stability of Flamingo Protein Complexes Underlies the Establishment of Planar Polarity. Curr Biol 2008, 18:1555-1564.

34. Struhl G, Casal J, Lawrence PA: Dissecting the molecular bridges that mediate the function of Frizzled in planar cell polarity. Development 2012, 139:3665-3674.

35. Bastock R, Strutt H, Strutt D: Strabismus is asymmetrically localised and binds to Prickle and Dishevelled during Drosophila planar polarity patterning. Development 2003, 130:3007-3014.

36. Wong HC, Bourdelas A, Krauss A, Lee HJ, Shao Y, Wu D, Mlodzik M, Shi DL, Zheng J: Direct binding of the PDZ domain of Dishevelled to a conserved internal sequence in the C-terminal region of Frizzled. Mol Cell 2003, 12:1251-1260.

37. Tree DRP, Shulman JM, Rousset R, Scott MP, Gubb D, Axelrod JD: Prickle mediates feedback amplification to generate asymmetric planar cell polarity signaling. Cell 2002, 109:371-381.

38. Jenny A, Reynolds-Kenneally J, Das G, Burnett M, Mlodzik M: Diego and Prickle regulate frizzled planar cell polarity signalling by competing for Dishevelled binding. Nat Cell Biol 2005, 7:691697.

* 39. Warrington SJ, Strutt H, Fisher KH, Strutt D: A Dual Function for Prickle in Regulating Frizzled Stability during Feedback-Dependent Amplification of Planar Polarity. Curr Biol 2017, 27:2784-2797.e3.

In this paper, the authors clarify the function of cytoplasmic core PCP proteins by using mosaic analysis combined with short-term overexpression in Drosophila wings. They show that Pk destabilizes Fz:Dsh when present in the same cell through endocytosis, but stabilize Fz in the neighboring cell by stabilizing Vang. Thus, Dsh protects $\mathrm{Fz}$ from endocytosis while $\mathrm{Pk}$ inhibits this interaction when present in the same cell.

40. Amonlirdviman K, Khare NA, Tree DRP, Chen WS, Axelrod JD, Tomlin CJ: Mathematical modeling of planar cell polarity to understand domineering nonautonomy. Science 2005, 307:423-426.

41. Fisher $\mathrm{KH}$, Strutt D, Fletcher AG: Experimental and Theoretical Evidence for Bidirectional Signaling via Core Planar Polarity Protein Complexes in Drosophila. iScience 2019, 17:49-66.

42. Ma D, Yang $\mathrm{C}$ hui, McNeill H, Simon MA, Axelrod JD: Fidelity in planar cell polarity signalling. Nature 2003, 421:543-547.

43. Matakatsu H, Blair SS: Interactions between Fat and Dachsous and the regulation of planar cell polarity in the Drosophila wing. Development 2004, 131:3785-3794.

44. Strutt H, Strutt D: Nonautonomous planar polarity patterning in Drosophila: Dishevelledindependent functions in frizzled. Dev Cell 2002, 3:851-863.

45. Ishikawa HO, Takeuchi H, Haltiwanger RS, Irvine KD: Four-jointed is a Golgi kinase that phosphorylates a subset of cadherin domains. Science 2008, 321:401-404. 
46. Brittle AL, Repiso A, Casal J, Lawrence PA, Strutt D: Four-Jointed Modulates Growth and Planar Polarity by Reducing the Affinity of Dachsous for Fat. Curr Biol 2010, 20:803-810.

47. Simon MA, Xu A, Ishikawa HO, Irvine KD: Modulation of Fat:Dachsous Binding by the Cadherin Domain Kinase Four-Jointed. Curr Biol 2010, 20:811-817.

48. Bateman J, Reddy RS, Saito H, Van Vactor D: The receptor tyrosine phosphatase Dlar and integrins organize actin filaments in the Drosophila follicular epithelium. Curr Biol 2001, 11:1317-1327.

49. Viktorinová I, König T, Schlichting K, Dahmann C: The cadherin Fat2 is required for planar cell polarity in the Drosophila ovary. Development 2009, 136:4123-4132.

50. Aw WY, Devenport D: Planar cell polarity: global inputs establishing cellular asymmetry. Curr Opin Cell Biol 2017, 44:110-116.

51. Fisher $\mathrm{KH}$, Strutt $\mathrm{D}$ : A theoretical framework for planar polarity establishment through interpretation of graded cues by molecular bridges. Development 2019, 146.

52. Adler PN, Krasnow RE, Liu J: Tissue polarity points from cells that have higher Frizzled levels towards cells that have lower Frizzled levels. Curr Biol 1997, 7:940-949.

53. Wu J, Roman AC, Carvajal-Gonzalez JM, Mlodzik $\mathrm{M}$ : Wg and Wnt4 provide long-range directional input to planar cell polarity orientation in Drosophila. Nat Cell Biol 2013, 15:10451055.

* 54. Ewen-Campen B, Comyn T, Vogt E, Perrimon N: No Evidence that Wnt Ligands Are Required for Planar Cell Polarity in Drosophila. Cell Rep 2020, 32:108121.

* 55. Yu JJS, Maugarny-Calès A, Pelletier S, Alexandre C, Bellaiche Y, Vincent JP, McGough IJ: FrizzledDependent Planar Cell Polarity without Secreted Wnt Ligands. Dev Cell 2020, 54:583-592.e5.

In ref. 54 and 55, the authors show by generating new mutant alleles by CRISPR that Wnt ligands are not required to align core PCP planar polarity in the Drosophila wing contrary to one of the historical hypothesis of the field.

56. Gao B, Song H, Bishop K, Elliot G, Garrett L, English MA, Andre P, Robinson J, Sood R, Minami Y, et al.: Wnt Signaling Gradients Establish Planar Cell Polarity by Inducing Vangl2 Phosphorylation through Ror2. Dev Cell 2011, 20:163-176.

57. Gao B, Ajima R, Yang W, Li C, Song H, Anderson MJ, Liu RR, Lewandoski MB, Yamaguchi TP, Yang $Y$ : Coordinated directional outgrowth and pattern formation by integration of wnt5a and Fgf signaling in planar cell polarity. Development 2018, 145.

58. Yang $\mathrm{CH}$, Axelrod JD, Simon MA: Regulation of Frizzled by Fat-like cadherins during planar polarity signaling in the Drosophila compound eye. Cell 2002, 108:675-688.

59. Sagner A, Merkel M, Aigouy B, Gaebel J, Brankatschk M, Jülicher F, Eaton S: Establishment of global patterns of planar polarity during growth of the drosophila wing epithelium. Curr Biol 2012, 22:1296-1301.

** 60. Aw WY, Heck BW, Joyce B, Devenport D: Transient Tissue-Scale Deformation Coordinates Alignment of Planar Cell Polarity Junctions in the Mammalian Skin. Curr Biol 2016, 26:20902100.

In this paper, the authors show that in mouse skin, core PCP axial asymmetry emerges due to a gradient of tissue deformation, as previously found in Drosophila. Flamingo being slow to accumulate on newly 
formed junctions and stable on persistent junctions, they propose that oriented cell intercalations generated by tissue strain result in a spontaneous symmetry breaking of Fmi.

61. Eaton S, Jülicher F: Cell flow and tissue polarity patterns. Curr Opin Genet Dev 2011, 21:747752.

62. Shimada Y, Yonemura S, Ohkura H, Strutt D, Uemura T: Polarized transport of Frizzled along the planar microtubule arrays in Drosophila wing epithelium. Dev Cell 2006, 10:209-222.

63. Harumoto $T$, Ito M, Shimada Y, Kobayashi TJ, Ueda HR, Lu B, Uemura T: Atypical cadherins dachsous and fat control dynamics of noncentrosomal microtubules in planar cell polarity. Dev Cell 2010, 19:389-401.

64. Matis M, Russler-Germain DA, Hu Q, Tomlin CJ, Axelrod JD: Microtubules provide directional information for core PCP function. Elife 2014, 3:1-17.

65. Chien $\mathrm{YH}$, Keller R, Kintner C, Shook DR: Mechanical strain determines the axis of planar polarity in ciliated epithelia. Curr Biol 2015, 25:2774-2784.

66. Classen AK, Anderson KI, Marois E, Eaton S: Hexagonal packing of Drosophila wing epithelial cells by the planar cell polarity pathway. Dev Cell 2005, 9:805-817.

67. Warrington SJ, Strutt $H$, Strutt D: The frizzled-dependent planar polarity pathway locally promotes E-cadherin turnover via recruitment of RhoGEF2. Development 2013, 140:10451054.

** 68. Cetera M, Leybova L, Joyce B, Devenport D: Counter-rotational cell flows drive morphological and cell fate asymmetries in mammalian hair follicles. Nat Cell Biol 2018, 20:541-552.

In this paper, the authors show that mouse hair follicles polarization depends on cell rearrangements driving counter-rotational cell flows. Core PCP proteins are required for these cell rearrangements, as well as ROCK/Myo-II. It is proposed that core PCP proteins polarize this process by activating Myo-II in a planar polarized manner, which directs cell rearrangements that create cell flows.

69. McGreevy EM, Vijayraghavan D, Davidson LA, Hildebrand JD: Shroom3 functions downstream of planar cell polarity to regulate myosin II distribution and cellular organization during neural tube closure. Biol Open 2015, 4:186-196.

70. Williams $M$, Yen $W$, Lu X, Sutherland A: Distinct apical and basolateral mechanisms drive planar cell polarity-dependent convergent extension of the mouse neural plate. Dev Cell 2014, 29:34-46.

71. Habas $\mathrm{R}$, Kato $\mathrm{Y}, \mathrm{He} \mathrm{X}$ : Wnt/Frizzled activation of Rho regulates vertebrate gastrulation and requires a novel formin homology protein Daam1. Cell 2001, 107:843-854.

72. Viktorinová I, Dahmann C: Microtubule polarity predicts direction of egg chamber rotation in Drosophila. Curr Biol 2013, 23:1472-1477.

73. Chen DY, Lipari KR, Dehghan Y, Streichan SJ, Bilder D: Symmetry Breaking in an Edgeless Epithelium by Fat2-Regulated Microtubule Polarity. Cell Rep 2016, 15:1125-1133.

74. Cetera M, Ramirez-San Juan GR, Oakes PW, Lewellyn L, Fairchild MJ, Tanentzapf G, Gardel ML, Horne-Badovinac S: Epithelial rotation promotes the global alignment of contractile actin bundles during Drosophila egg chamber elongation. Nat Commun 2014, 5.

75. Mao Q, Lavalou J, Lecuit T: Fat2 and Lar Dance a Pas de Deux during Collective Cell Migration. Dev Cell 2017, 40:425-426. 
76. Haigo SL, Bilder D: Global tissue revolutions in a morphogenetic movement controlling elongation. Science 2011, 331:1071-4.

77. Lewellyn L, Cetera M, Horne-Badovinac S: Misshapen decreases integrin levels to promote epithelial motility and planar polarity in Drosophila. J Cell Biol 2013, 200:721-729.

78. Ambegaonkar AA, Pan G, Mani M, Feng Y, Irvine KD: Propagation of dachsous-fat planar cell polarity. Curr Biol 2012, 22:1302-1308.

79. Brittle A, Thomas C, Strutt D: Planar polarity specification through asymmetric subcellular localization of fat and dachsous. Curr Biol 2012, 22:907-914.

80. Hale R, Brittle AL, Fisher KH, Monk NAM, Strutt D: Cellular interpretation of the long-range gradient of Four-jointed activity in the Drosophila wing. Elife 2015, 2015:1-21.

81. Jolly MK, Rizvi MS, Kumar A, Sinha P: Mathematical modeling of sub-cellular asymmetry of fatdachsous heterodimer for generation of planar cell polarity. PLOS One 2014, 9.

82. Paré AC, Vichas A, Fincher CT, Mirman Z, Farrell DL, Mainieri A, Zallen JA: A positional Toll receptor code directs convergent extension in Drosophila. Nature 2014, 515:523-527.

83. Scholz N, Gehring J, Guan C, Ljaschenko D, Fischer R, Lakshmanan V, Kittel RJ, Langenhan T: The Adhesion GPCR Latrophilin/CIRL Shapes Mechanosensation. Cell Rep 2015, 11:866-874.

84. Scholz N, Guan C, Nieberler M, Grotemeyer A, Maiellaro I, Gao S, Beck S, Pawlak M, Sauer M, Asan $E$, et al.: Mechano-dependent signaling by latrophilin/CIRL quenches CAMP in proprioceptive neurons. Elife 2017, 6:1-21.

85. Langenhan T: Adhesion $\mathbf{G}$ protein-coupled receptors-Candidate metabotropic mechanosensors and novel drug targets. Basic Clin Pharmacol Toxicol 2019, 126:5-16.

86. Fernandez-Gonzalez R, Simoes S de M, Röper JC, Eaton S, Zallen JA: Myosin II Dynamics Are Regulated by Tension in Intercalating Cells. Dev Cell 2009, 17:736-743.

87. Yu HH, Zallen JA: Abl and Canoe/Afadin mediate mechanotransduction at tricellular junctions. Science 2020, 370.

88. Strutt $\mathrm{H}$, Strutt $\mathrm{D}$ : How do the Fat-Dachsous and core planar polarity pathways act together and independently to coordinate polarized cell behaviours? Open Biol 2021, 11:200356.

89. Casal J, Lawrence PA, Struhl G: Two separate molecular systems, Dachsous/Fat and Starry night/Frizzled, act independently to confer planar star polarity. Development 2006, 133:45614572.

90. Merkel M, Sagner A, Gruber FS, Etournay R, Blasse C, Myers E, Eaton S, Jülicher F: The balance of prickle/spiny-legs isoforms controls the amount of coupling between core and fat PCP systems. Curr Biol 2014, 24:2111-2123.

91. Mao Y, Mulvaney J, Zakaria S, Yu T, Morgan KM, Allen S, Basson MA, Francis-West P, Irvine KD: Characterization of a Dchs1 mutant mouse reveals requirements for Dchs1-Fat4 signaling during mammalian development. Development 2011, 138:947-957.

92. Saburi S, Hester I, Fischer E, Pontoglio M, Eremina V, Gessler M, Quaggin SE, Harrison R, Mount $\mathrm{R}, \mathrm{McNeill} \mathrm{H}$ : Loss of Fat4 disrupts PCP signaling and oriented cell division and leads to cystic kidney disease. Nat Genet 2008, 40:1010-1015.

93. Horne-Badovinac S: Fat-like cadherins in cell migration-leading from both the front and the back. Curr Opin Cell Biol 2017, 48:26-32. 
94. Dolan J, Walshe K, Alsbury S, Hokamp K, O'Keeffe S, Okafuji T, Miller SFC, Tear G, Mitchell KJ: The extracellular Leucine-rich repeat superfamily; a comparative survey and analysis of evolutionary relationships and expression patterns. BMC Genomics 2007, 8:1-24.

95. Karaulanov EE, Böttcher RT, Niehrs C: A role for fibronectin-leucine-rich transmembrane cellsurface proteins in homotypic cell adhesion. EMBO Rep 2006, 7:283-290.

96. Tomás AR, Certal AC, Rodríguez-León J: FLRT3 as a key player on chick limb development. Dev Biol 2011, 355:324-333. 
macroscopic process

(a) proximal $\longleftrightarrow$ distal

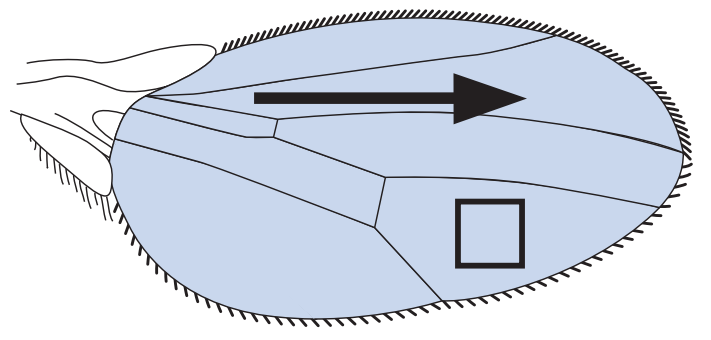

(b) anterior $\longleftrightarrow$ posterior

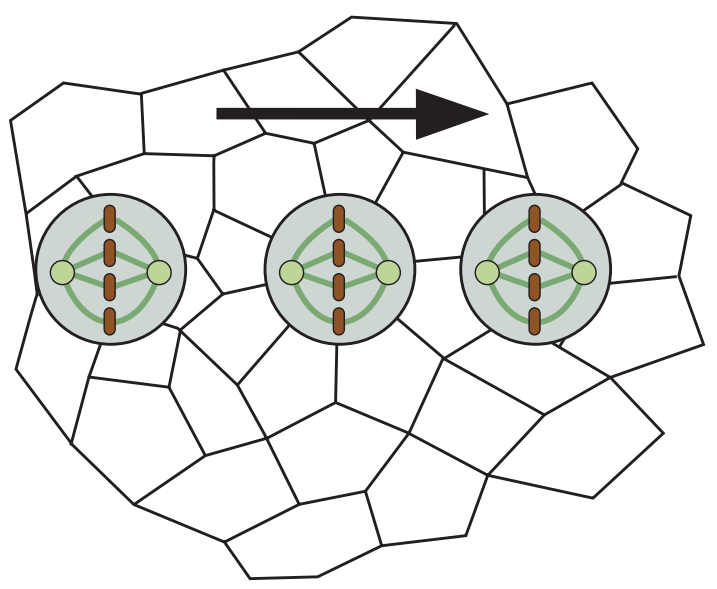

(c)

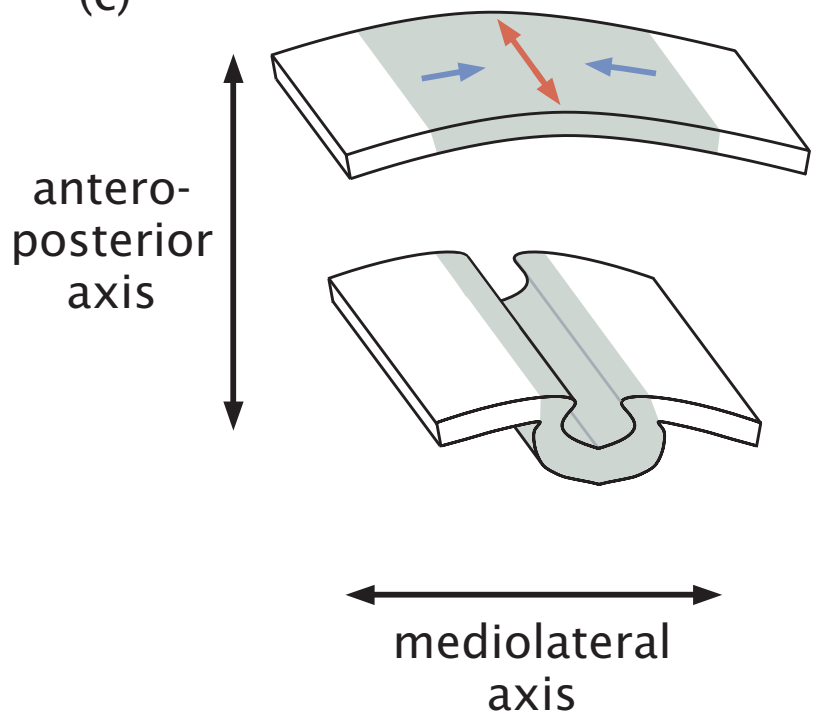

(a')

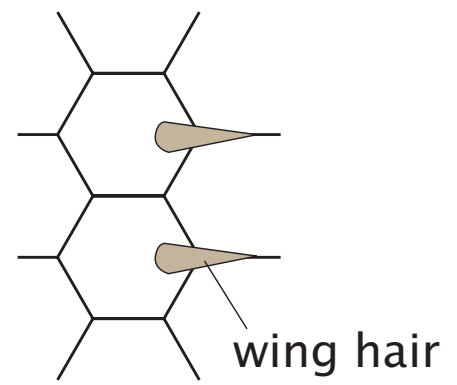

(b') mitotic spindle

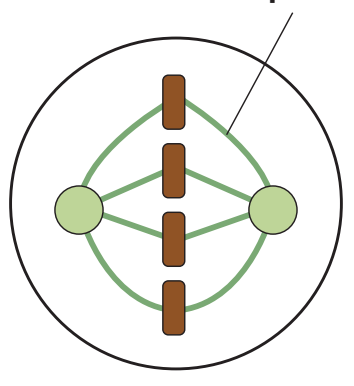

(c')
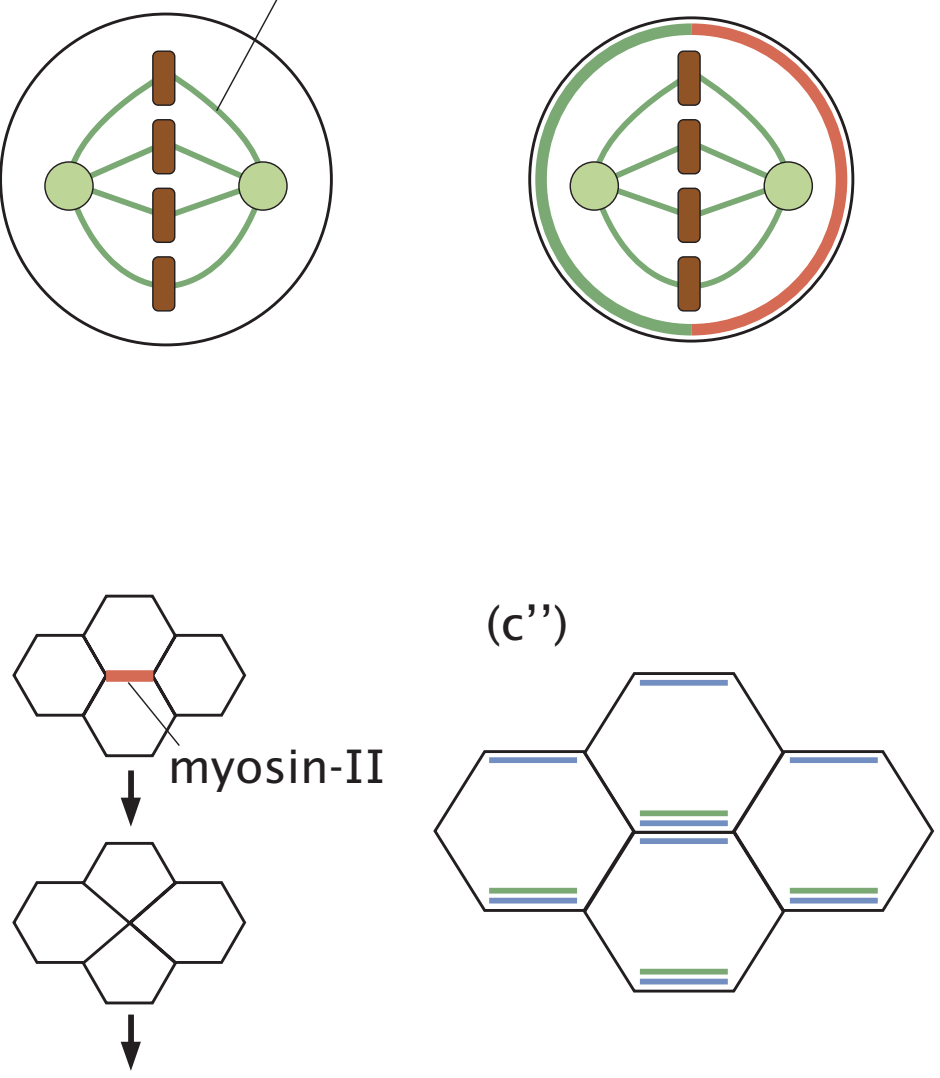

(b')

\section{PCP proteins}

(a")

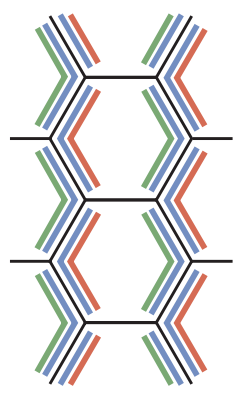

- Fmi

- Fz Vang

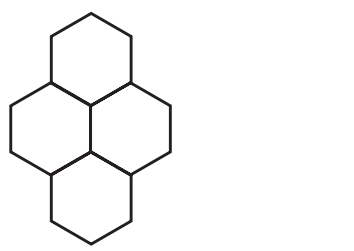


Figure 1: Examples of PCP processes controlled by the core PCP pathway.

(a) Wing hairs are aligned on the adult Drosophila wing. The square box in (a) is zoomed in $\left(a^{\prime}\right)$. $\left(a^{\prime}\right)$ Every wing cell protrudes a single hair at the distal tip of the cell that points distally. (a") This pattern is controlled by the core PCP pathway. Core PCP proteins are asymmetrically distributed along the anteroposterior axis as indicated.

(b) Oriented cell divisions of sensory organ precursor cells (SOPs) on the pupal Drosophila notum. (b') The mitotic spindle of each SOP is aligned along the plane of the epithelium and thus SOPs divide in an oriented manner. (b") Asymmetric distribution of core PCP proteins in SOPs orients the mitotic spindle along the anteroposterior axis.

(c) The formation of the vertebrate neural tube involves a convergent extension process. The tissue shrink along the mediolateral axis (blue arrows) and extend along the anteroposterior axis (red arrow). ( $\mathbf{c}^{\prime}$ ) Myosin-II (Myo-II) is planar polarized, which powers planar polarized cell intercalation driving tissue extension. (c") Asymmetric distribution of core PCP proteins induces Myo-II planar polarity.

Fmi: Flamingo; Fz: Frizzled; Vang: Van Gogh. 


\section{macroscopic process}

(a)

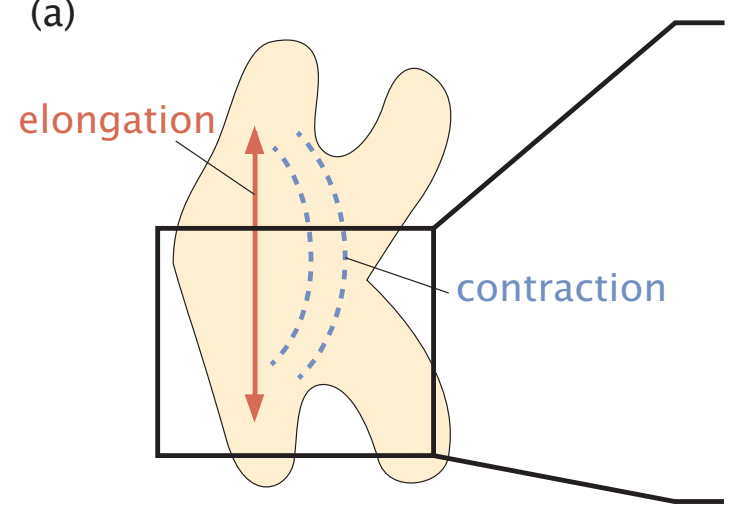

(b)

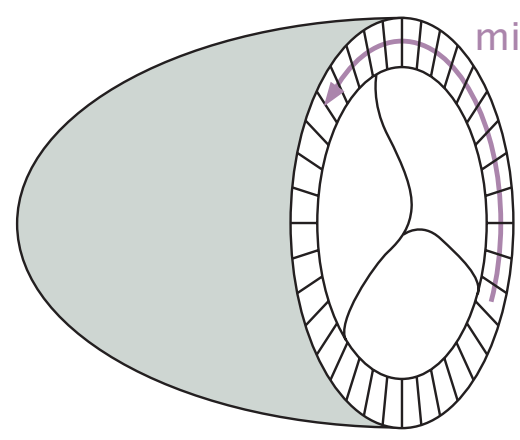

(c)
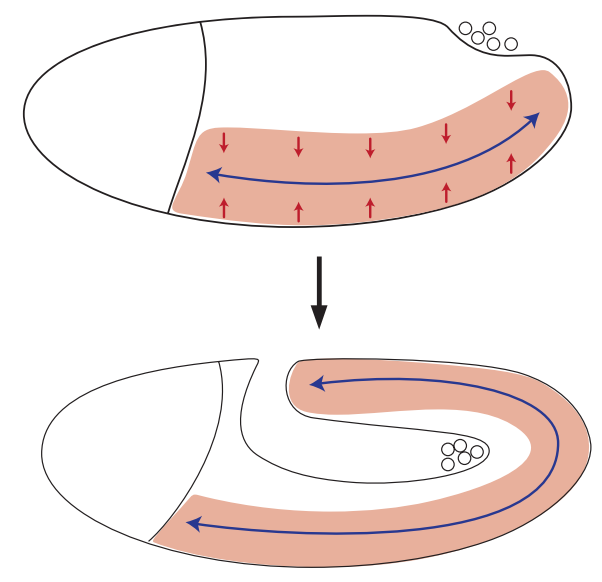

\section{cellular polarity}

(a')

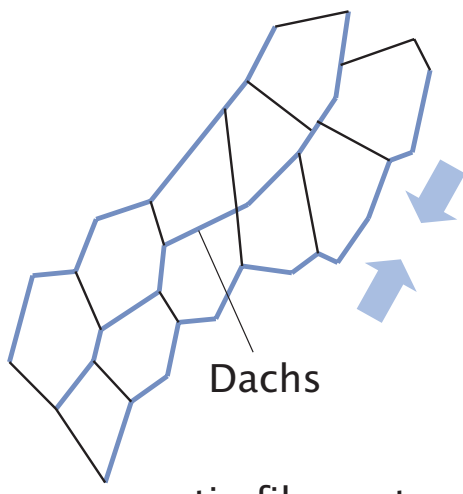

(b')

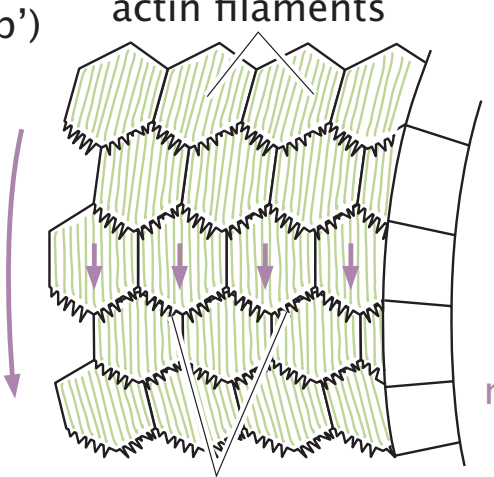

actin protrusions
PCP proteins

(a")

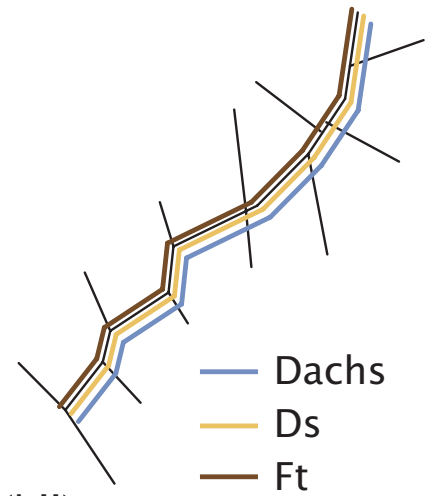

(b")

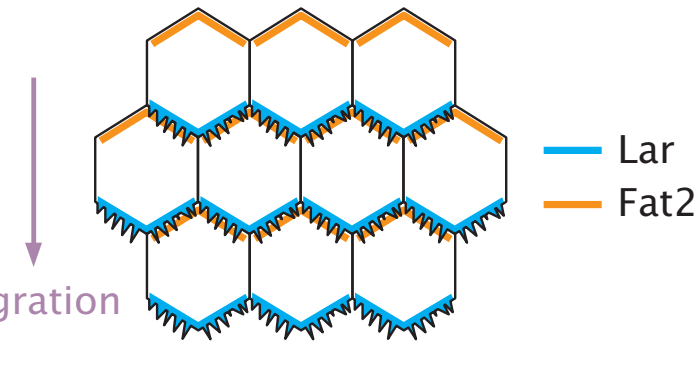

(c')

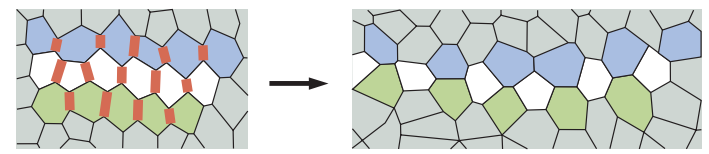

$x-x-x$

Myo-II (c')

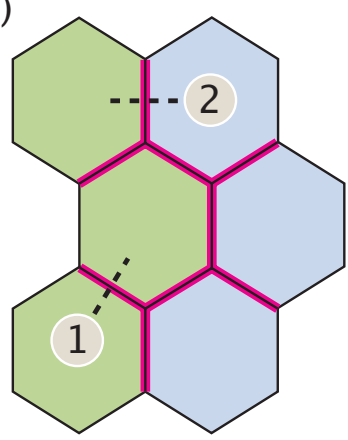

$\begin{array}{ll}\text { Cirl } & \text { different } \\ \text { combinations of } \\ \text { Toll receptors }\end{array}$

1
2

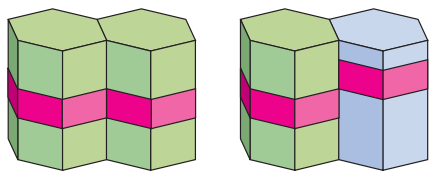


Figure 2: Examples of PCP processes controlled by the other PCP pathways.

(a) Morphogenesis of the Drosophila scutellum during thorax metamorphosis. (a') The atypical myosin Dachs is planar polarized and induces a planar polarized pattern of contractions and cell rearrangements (blue arrows). (a") Asymmetric distribution of Ft and Ds induces Dachs planar polarity.

(b) Collective migration in Drosophila egg chambers. (b') Actin filaments are aligned within the plane of the tissue and actin protrusions are planar polarized, which drives collective cell migration and tissue rotation. (b") Asymmetric distribution of Fat2 and Lar controls actin polarization. Lar accumulates at the cell leading edges while Fat2 accumulates at the trailing edges.

(c) Tissue extension in early Drosophila embryos. This tissue shrink along one axis (red arrows) and extend along the perpendicular exis (blue arrows). ( $\mathbf{c}^{\prime}$ ) This process is driven by planar polarized cell intercalation depending on planar polarized junction remodeling: "vertical" junctions shrink while new "horizontal" junctions grow perpendicularly (top). Myosin-II (Myo-II) is planar polarized along "vertical" junctions, which drives the shrinkage of these junctions (bottom). (c") Myo-Il accumulates between neighboring cells expressing different combination of Toll receptors, which requires an interfacial asymmetry in Cirl apicobasal localization. It is hypothesized that Cirl is symmetrically localized between cells expressing the same combination of Toll receptors (case 1, left) while it is asymmetrically localized along the apicobasal axis between cells expressing different combination of Toll receptors (case 2, right), explaining how Myo-Il is specifically polarized along "vertical" junctions.

Ft: Fat; Ds: Dachsous. 
(a)

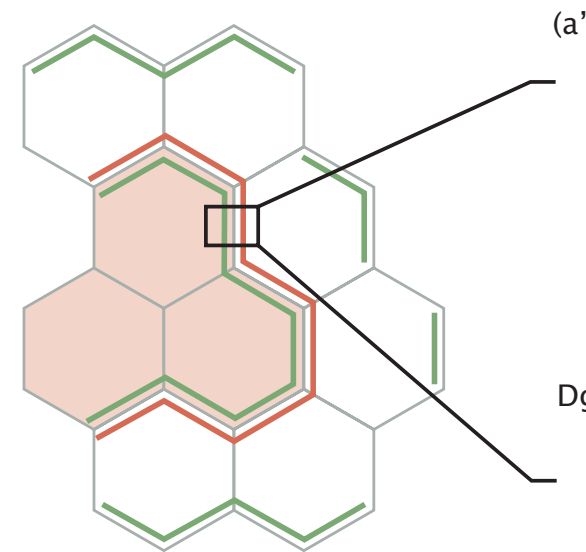

$\square$ vang $-/-$ Fz

(b)

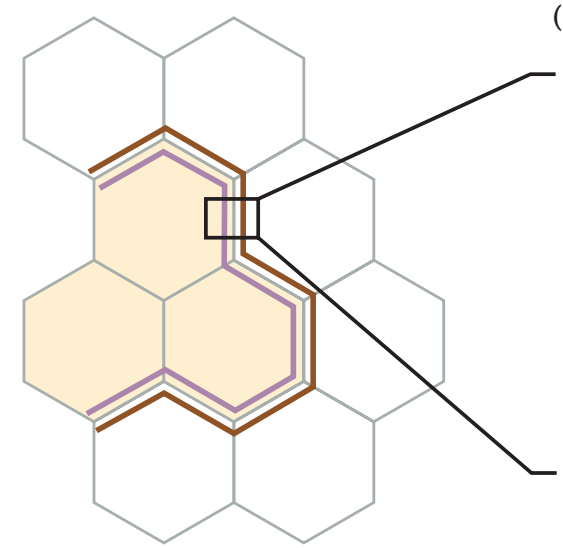

$\square$ fat $-1-\quad$ Ds (a')

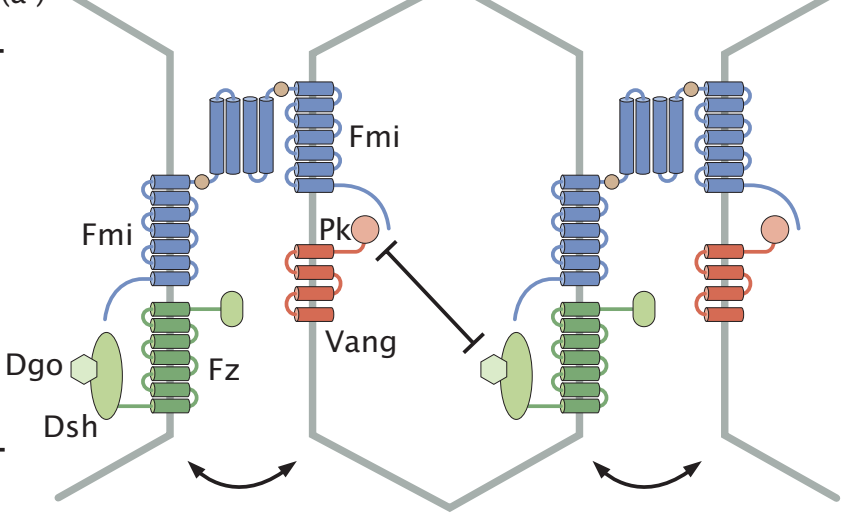

(b')

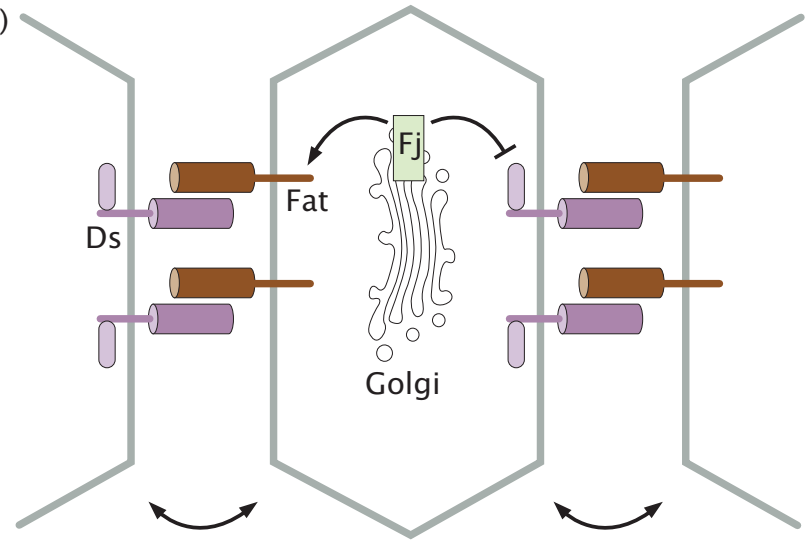

(c')

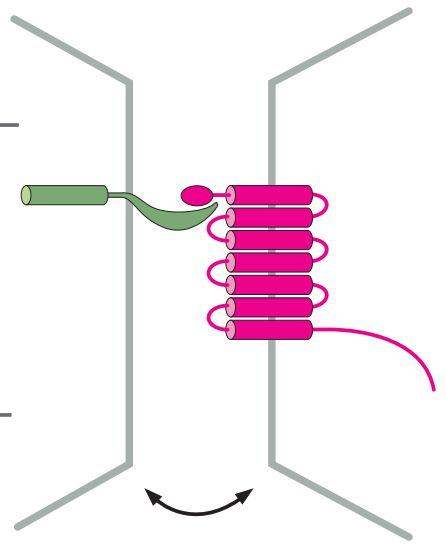

(c)

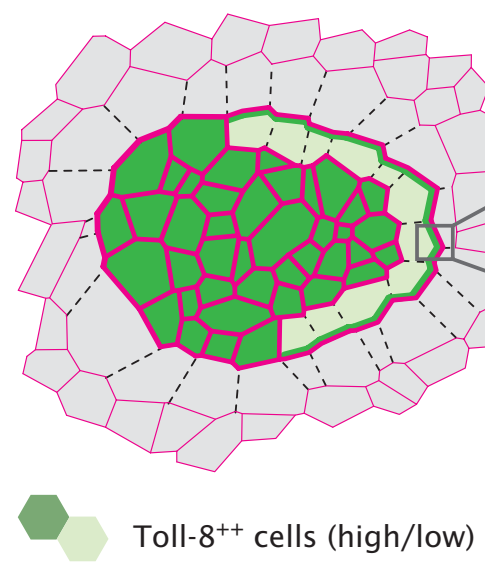

WT cells - Cirl

(d)

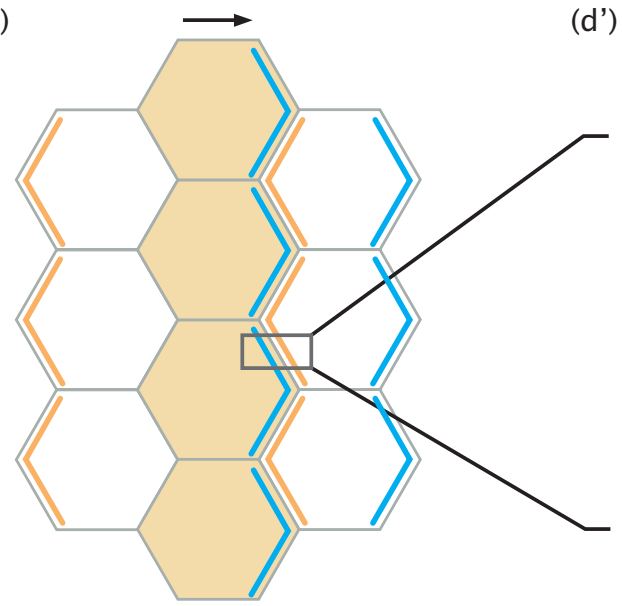

$\checkmark$ fat $-1-$ (d')

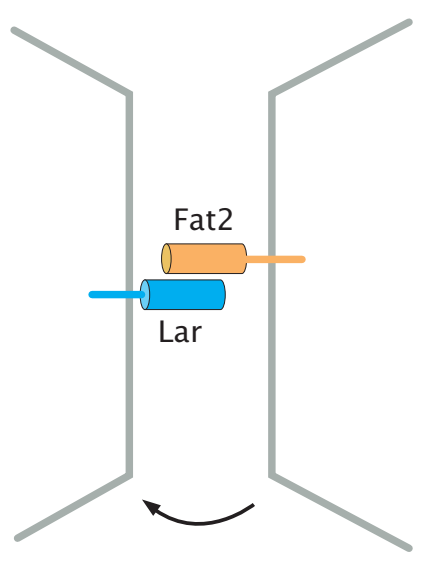


Figure 3: Local interactions between asymmetric planar polarity complexes.

(a) Core PCP proteins are asymmetrically distributed the boundary of a vang mutant clone. (a') This polarization depends on feedback interactions between core PCP proteins. Fmi:Fz complex in one cell interact preferentially with Fmi:Vang complex in the adjacent cell. Cytoplasmic core PCP proteins (Dsh, Dgo and Pk) reinforce planar polarity by antagonizing one another within the cell.

(b) Ft and Ds are asymmetrically distributed at the boundary of a fat mutant clone. (b') Ft and Ds are preferentially interact in trans between neighboring cells. $\mathrm{Fj}$, a Golgi kinase, phosphorylates the cadherin domains of Ft and Ds, which increases the affinity of Ft for Ds and decreases the affinity of Ds for Ft.

(c) Cirl is planar polarized in trans from the neighboring wild-type cells at the boundary of a Toll-8 overexpressing clone (left). Moreover, quantitative differences in Toll-8 expression between neighboring cells leads to Toll-8 planar polarity inducing Cirl planar polarity in trans (right). (c') Toll-8 and Cirl form a molecular complex and mutually attract each other in trans between neighboring cells.

(d) Lar planar polarity is lost in the cells "behind" fat2 mutant clones. The arrow indicates the direction of tissue migration. (d') Fat2 and Lar interact with each other in trans and Fat2 is required for Lar planar polarity. However, contrary to the situation found in the other PCP pathways, Lar is not required for Fat2 planar polarity.

Fmi: Flamingo; Fz: Frizzled; Vang: Van Gogh; Dsh: Dishevelled; Dgo: Diego; Pk: Prickle; Ft: Fat; Ds: Dachsous; Fj: Four-joint. 
(a)

\section{tissue} strain

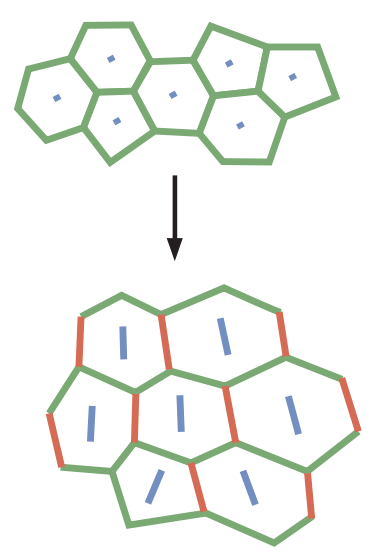

PCP proteins

new junctions

PCP axis (a')

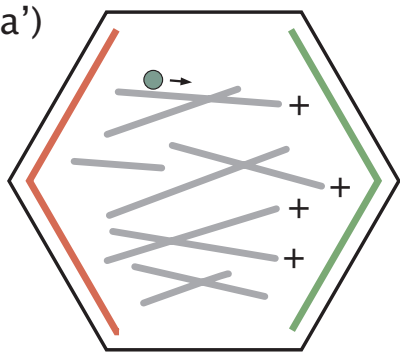

- Fz

_ Vang

microtubules (b)

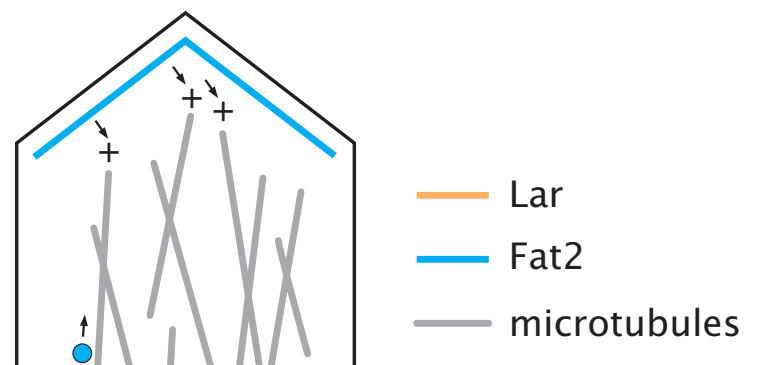

(c)

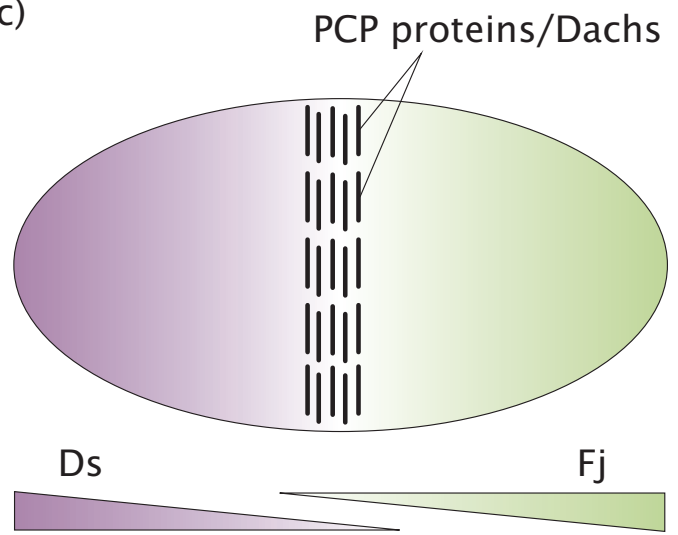

$\longrightarrow$ transcriptional $\longleftarrow$ gradients (d)

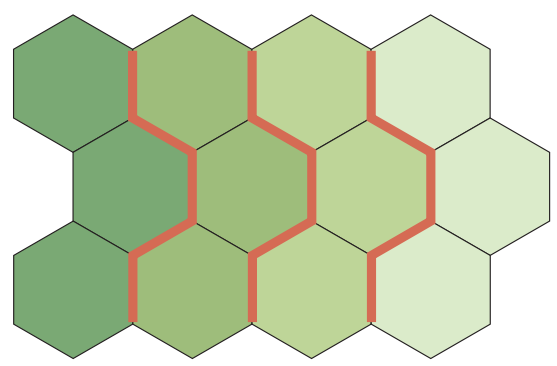

PCP proteins/Myo-II

Toll-8

$\longrightarrow$ transcriptional gradient 
Figure 4: Global alignment and propagation of planar polarity.

(a) Morphogenetic movement can lead to spontaneous symmetry breaking and axial polarization of core PCP proteins. Tissue strain induces oriented cell intercalations, and core PCP proteins are stable at persistent junctions but accumulate slowly at newly-formed junctions. The direction of tissue strain can thus define the axis of polarity of core PCP proteins. (a') Microtubule orientation can induce a vectorial polarity of core PCP proteins. Microtubules plus-end are polarized on one side of the cell and Fz particles move toward the direction of microtubules plus-end in a microtubule-dependent manner.

(b) Microtubule orientation can also induce vectorial polarization of Fat2. Microtubules plus-end are polarized on one side of the cell and Fat2 accumulates on this side in a microtubule-dependent manner. Moreover, Fat2 is required for microtubule plus-end polarization (small arrows), indicating a bidirectional relationship.

(c) Ds and Fj are expressed as tissue-wide opposing transcriptional gradients. Ft and Ds are polarized in regions where these two gradients intersect, which leads to the polarized recruitment of the atypical myosin Dachs by Ds.

(d) Quantitative differences in Toll-8 expression levels between neighboring cells induces Toll8/Cirl/Myo-II planar polarity. The direction of Toll-8 transcriptional gradient directs the orientation of Toll-8/Cirl/Myo-II planar polarity.

Fz: Frizzled; Vang: Van Gogh; Ds: Dachsous; Fj: Four-joint; Ft: Fat. 